\title{
Bending moment and axial force interacting on solid timber beams
}

\author{
R. Steiger ${ }^{1}$ and M. Fontana ${ }^{2}$ \\ (1) Empa, Swiss Federal Laboratories for Materials Testing and Research, Wood Laboratory, Überlandstrasse 129, CH-8600 \\ Dübendorf, Switzerland \\ (2) ETHZ, Swiss Federal Institute of Technology, Zurich, Switzerland
}

Received: 2 November 2004; accepted: 28 January 2005

\begin{abstract}
This paper describes the results of bending moment $(\mathrm{M})$ and axial force $(\mathrm{N})$ interaction tests on 220 solid spruce specimens with crosssection $80 \times 160 \mathrm{~mm}$. Depending on the timber strength, existing design models for $\mathrm{M} / \mathrm{N}$-interaction are fitted to the test results and different analytical approaches for the magnification or reduction of the initial moment due to beam deflections are evaluated. Interaction graphs of timber columns subjected to simultaneous action of bending moment and axial force exhibit convex curvilinearity viewed from the basis of the diagram. The degree of convexity depends on the slenderness of the column and on the strength of the timber. In the case of stocky columns subjected to high bending moments and small axial forces, the highest deviation from linearity can be observed. Design models published in standards and in literature describe the non-linearity of the interaction curve on the basis of an elastic stress-strain relationship in the tension portion of the cross-section and by a non-linear, "plastic" behaviour of the compression zone. Majority of former tests were performed on timber beams with small cross-section. For the case of interaction of bending and tension stress, only a limited number of results are available, because of the difficulty to apply high tension forces.

1359-5997 @ 2005 RILEM. All rights reserved.

\section{RÉSUMÉ}

Cet article présent les résultats de 220 essais vérifiant l'effet de l'interaction entre un moment de flexion (M) et un effort normal ( $N$ ) agissant en même temps sur des poutres du bois massif d'épicéa de section $80 \times 160 \mathrm{~mm}$. Les résultats sont comparés avec des modèles de dimensionnement en cas d'interaction $M / N$ et différentes estimations de l'amplification ou de la réduction du moment de flexion initial provoquées par les déformations de la poutre, sont évaluées. Les courbes d'interaction $M / N$ sont convexes par rapport à l'origine des axes, avec une déviation du modèle linéaire en particulier dans le cas de grands moments et petits efforts normaux. L'ampleur de cette convexité dans la courbe d'interaction dépend de l'élancement de la poutre et de la qualité du matériau. Les modèles de dimensionnement qui résultent des essais considèrent la non linéarité des courbes d'interaction à l'aide d'un comportement élastique en traction et plastique en compression. Beaucoup d'essais décrits dans la littérature se basent sur des éprouvettes de petites dimensions, En plus il y a très peu de données pour le cas de flexion avec traction, car l'application de grands efforts de tractions est difficile.
\end{abstract}

\section{INTRODUCTION}

When designing structural timber elements subjected to bending moments $M$ and axial forces $N$, such as eccentrically or transversely loaded columns, chords and frame members of truss girders, curved beams and rigid frames, engineers are facing the problem of the interaction of bending moments and axial forces. Most of the older design models and codes suggest a linear interaction of bending moment and axial force, which in case of high bending moments and moderate compression forces that are simultaneously acting on stocky columns presents a conservative approach, since the interaction in that case is considerably non-linear. The degree of non-linearity of the interaction curve depends on the slenderness of the column, on the ratio of flexural and axial stresses and on the strength of the timber. Recent models, derived from theoretical and experimental investigation, describe the non-linearity of the interaction curves on the basis of elastic stress-strain relationship in the tension portion of the cross-section and by a non-linear ("plastic") behaviour in the compression zone.

Normal grade timber sections with a certain amount of 
natural defects, such as knots or significant deviation of grain to beam axis, exhibit brittle failure of the tension zone, when stressed exclusively in flexion or simultaneously with an axial tension force. A linear model according to Equation (1) for the interaction of bending and axial stresses therefore appropriately describes this situation:

$$
\frac{\sigma_{t, 0}}{f_{t, 0}}+\frac{\sigma_{m}}{f_{m}} \leq 1
$$

$\sigma_{t, 0}=$ tensile stress parallel to the grain

$f_{t, 0}=$ tensile strength parallel to the grain

$\sigma_{m}=$ bending stress

$f_{m}=$ bending strength

Bending failure of high strength timber (which is actually a failure of the tension zone as well) might be preceded by a "plasticization" of the compression zone of the beam, provoking a downwards shift of the neutral axis (Fig. 1, [1]). The degree of non-linearity of the interaction diagram is therefore directly related to the ratio $\eta_{r}$ of the tension $f_{l, 0}$ and the compression strength $f_{c, o}$ of the timber, i.e. by its grade. Columns loaded by bending moment and compression force tend to develop "plastic" deformations of the compression zone. The European standard EN 1995-1-1 [2] for example takes this into account by setting the axial compression part within the interaction model to the power of 2 (Equation (2)).

$\left(\frac{\sigma_{c, 0}}{f_{c, 0}}\right)^{2}+\frac{\sigma_{m}}{f_{m}} \leq 1$

$\sigma_{c, 0}=$ compressive stress parallel to the grain

$f_{c, 0}=$ compressive strength parallel to the grain

$\sigma_{m}=$ bending stress

$f_{m}=$ bending strength

Good correspondence of theoretical models and experimental results is achieved by considering the volumerelated brittle behaviour on the beam's tension zone and the
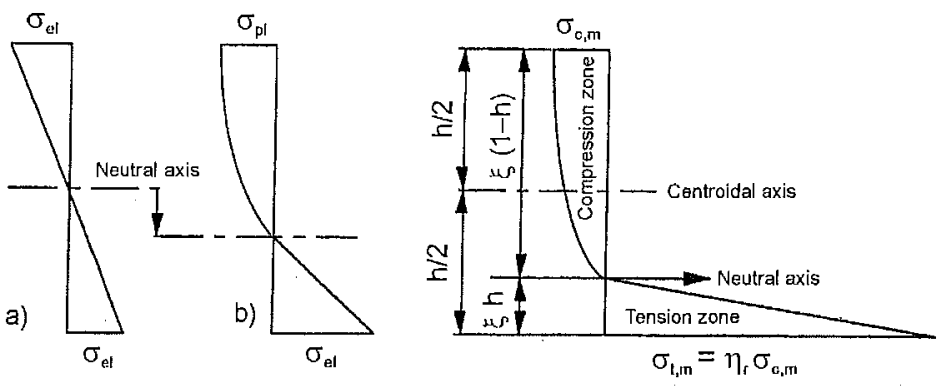

Fig. 1 - Stress-strain relationship of clear wood according to Zakic [1]. Linear (a) and non-linear model (b).

$\sigma_{e l}=$ extreme fibres normal stress in the elastic range

$\sigma_{p l}=$ extreme fibres normal stress in the plastic range

$\sigma_{c, m}=$ normal stress at extreme fibres of compression side of cross-section for fully plastic case caused by bending moments

$\sigma_{t, m}=$ normal stress at extreme fibres of tension side of cross-section caused by bending moments

$h=$ depth of the beam

$\xi=$ defines the position of the neutral axis for bending moment in the plastic range

$\eta_{r}=$ ratio of tension strength $f_{t, 0}$ to compression strength $f_{c, 0}$ non-linear stress-strain relationship of the compression zone.

While former research on $\mathrm{M} / \mathrm{N}$-interaction was almost completely based on tests on small specimens having no structural defects, recent publications deal with tests of timber beams having structural sizes $[3-9,11]$. In the case of pure tension force or simultaneously acting bending moment and tension force on large cross-sections, there is only a limited number of data available, since the introduction of high tension force into the test specimens is very difficult. The design of laterally loaded timber columns has always been of great interest and a number of theoretical and experimental studies were focused on that subject ([3] as an example). Important tests on the interaction of bending moment and axial force were performed by Senft and Suddarth $[4,5]$ and by Buchanan [6-8]. The latter showed that a linear model to describe interacting bending moment and compression force is a conservative approach. Based on equilibrium of tension and compression stresses within the cross-section for different position of the neutral axis, Buchanan suggested several design models, which consider inelastic bending and size effect. The model constants are calibrated on the basis of the test results and the significance of non-linearity of the interaction curves is emphasized by an elastic model in the tension portion of the cross-section of the beam and by a plastic stress distribution of the compression zone. The ratio of stress and strain (i.e. the modulus of elasticity MOE) is taken to be identical for both cases of tension and compression, which is a common assumption when designing timber structural elements, since the difference between the MOE in tension and compression is small. The design approach of timber columns according to European standard EN 1995-1-1 [2] is based on tests and numerical (Monte Carlo and Finite element) simulations by Blass [9]. Blass used a stochastic model to quantify the parameters of the model, which influence the material properties (stiffness and strength) and the geometrical imperfections. He takes into account the non-linearity of the stress-strain relationship in the compression zone by applying a model developed by Glos [10]. Kessel et al. [11] examined the load carrying behaviour of spruce columns with cross-section $100 \mathrm{x}$ $140 \mathrm{~mm}$ under combined axial and lateral loading. The columns were modelled in a geometrically and physically non-linear finite element analysis. Scattering and correlation of the input data was taken into account in numerical determination of the diagram when generating the $\mathrm{M} / \mathrm{N}$-interaction curves numerically for three different ratios of slenderness. Kessel et al. also reported a nonlinearity of the $\mathrm{M} / \mathrm{N}$-interaction graph in the bending-compression quadrant.

This paper is the result of a major research project [12-14] and describes the results of 220 $\mathrm{M} / \mathrm{N}$-interaction tests on solid spruce beams with a cross section of $80 \times 160 \mathrm{~mm}$ and a length of $3 \mathrm{~m}$. In order to evaluate the influence of timber strength on the test results, two samples of clearly distinct EN 338 [15] 
strength classes C27 ("normal strength timber") and C40 ("high strength timber") were tested. Existing design modeis and approaches for the magnification or reduction of the initial bending moment due to column deflections were then compared to the test results.

\section{TEST PROCEDURE AND MATERIAL}

\subsection{Equipment}

Interacting bending moment $M$ and axial force $N$ can be applied to the specimens by either an eccentric axial force, by simultaneous axial and lateral loading or by bending moments at both ends of a tension or compression element. The appropriate solution depends on the type of the structural element (column, truss element, joint, etc.) and on its geometrical proportions (length, cross-section), as well as on the ratio of bending moment and axial force. Within this study the tests with pure axial force $(M=0)$ were carried out using a universal tension and compression testing machine. Applying the necessary high tension forces of up to $350 \mathrm{kN}$ required the development of an adequate clamping device (Fig. 2) [12]. In pure compression tests the specimens were laterally supported to prevent weak-axis buckling (Fig. 3).

The $\mathrm{M} / \mathrm{N}$-interaction tests were performed using a special experimental set up (Fig. 4) [13], simulating a beam column situation: a tensile or compressive axial force was applied together with an initial bending moment $M^{I}$ as a consequence of two lateral loads $F$ acting in points of one third of the span. The span was $\ell=\ell_{c r}=2760 \mathrm{~mm}$, which corresponds to a spanto-depth ratio of $\ell / h=17.25$ and a slenderness ratio of $\lambda_{k}=\ell_{c r} i$ $=60$. This configuration has the advantage of being a well defined static system with fixed working lines of the external forces. The MOE was calculated from deflection measurements between the action points of the two lateral forces. The axial force $N$ was applied to the specimens by a pair of steel plates with ribbed surfaces, which were pressed onto the timber (Fig. 5). To prevent specimens from weak-axis buckling (out of plane), the beams were laterally supported by steel elements (Fig. 4). Beside the tests with pure axial loads (tension or compression), 9 series with different ratios of axial and lateral forces $k=N / F$ were carried out. Each sub series consisted of 10 . tests. A constant ratio $\mathrm{k}$ of axial to lateral force was realized by coupling both hydraulic system and by using adequate pressure reduction valves.

\subsection{Sampling}

In order to study the influence of the timber strength on the interaction curves, the tests were carried out on two samples of clearly different EN338-grades C27 and C40 [15]. All specimens were ranked according to the velocity of an. ultrasonic wave, propagating in the longitudinal direction of the specimen (Fig. 6) [14]. This method guaranteed a reliable estimation of the specimens' stiffness and strength. The selection of material for the two grades and the values of scattering of data within the two selected samples were

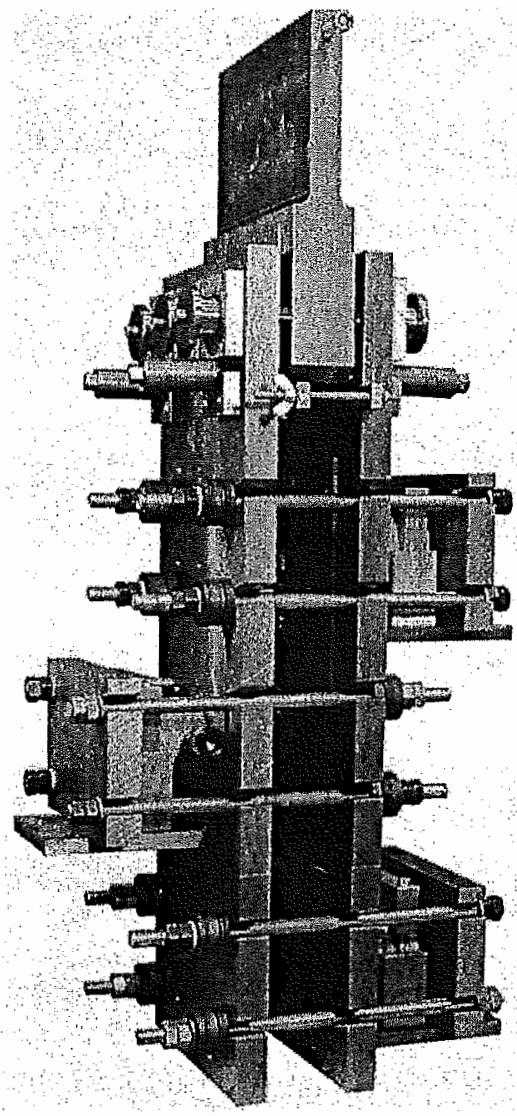

Fig. 2 - Grips for tension tests. (Specimens of cross section up to $120 \times 200 \mathrm{~mm}$ can be tested in tension with forces up to $1400 \mathrm{kN}$ ).

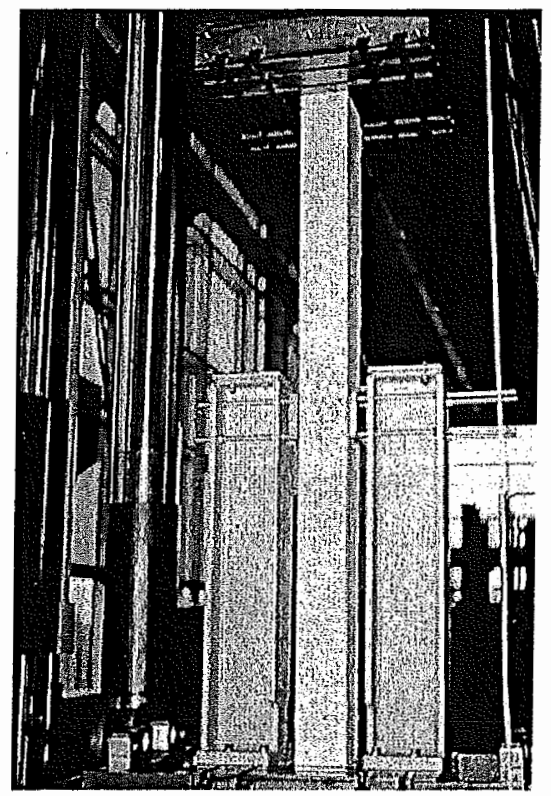

Fig. 3 - Specimen tested in pure compression, laterally supported to prevent buckling failure.

arbitrarily performed in attempt to imitate the distributions that appear in practical conditions. The statistical parameters of the MOE derived from mechanical tests are given in Table 1. 

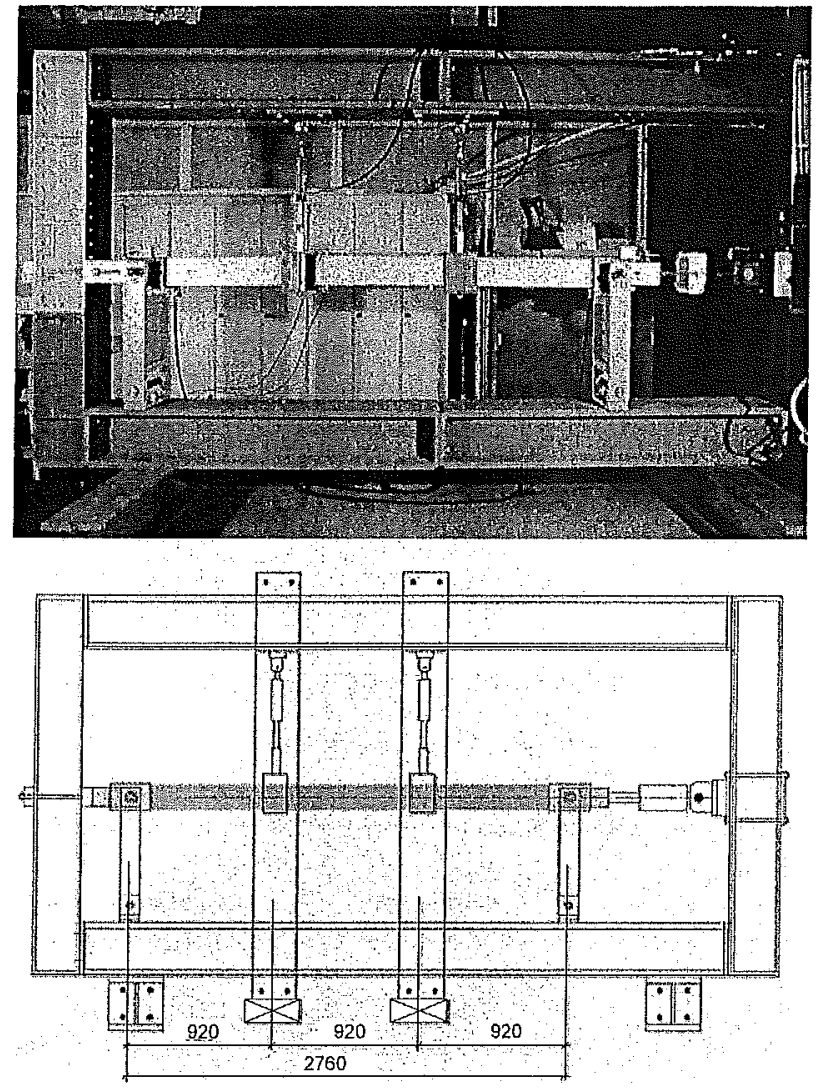

Fig. 4 - Test set up for $\mathrm{M} / \mathrm{N}$-interaction tests. To prevent the buckling of specimens subjected to combined flexural and compressive load, lateral steel supports were added.

Thus the preliminary grouping of specimens on the basis of their moduli of elasticity, determined by ultrasonic grading, resulted in reduced variability of data within all sub groups of specimens. This additionally reduced the required sample size for reliable testing.

\section{RESULTS AND DISCUSSION}

\subsection{Influence of timber strength}

Figs. 7 and 8 present the test results for each sub group of samples together with the interaction lines both on the $5^{\text {th }}$ percentile and on the mean level. The shape of the interaction curve obviously depends on the timber strength. With increasing strength the culmination point of the curves for the mean values tends to shift to the bending-tension-quadrant. However on the $5^{\text {th }}$ percentile level, on which the design of timber structural elements is actually based, no difference between the two grades $\mathrm{C} 27$ and $\mathrm{C} 40$ can be observed. It is therefore appropriate to assume that a linear model may be adopted to describe the interaction of bending moment with tension loads. This is also valid for high compression forces and noderate bending moments. In the sector of high moment values and low to moderate compression forces, the interaction curve clearly deviates from a linear line for slenderness ratios less than 70, which was also found by Buchanan [7] and can

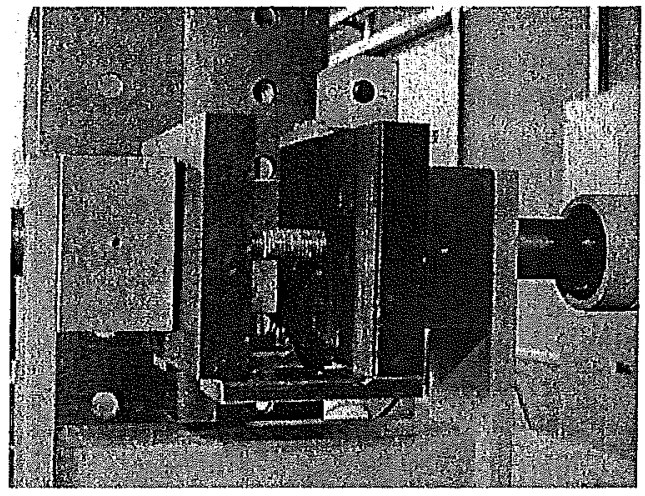

Fig. 5 - Detailed view of the support. Axial forces were applied by a pair of steel plates with ribbed surface, pressed onto the timber.

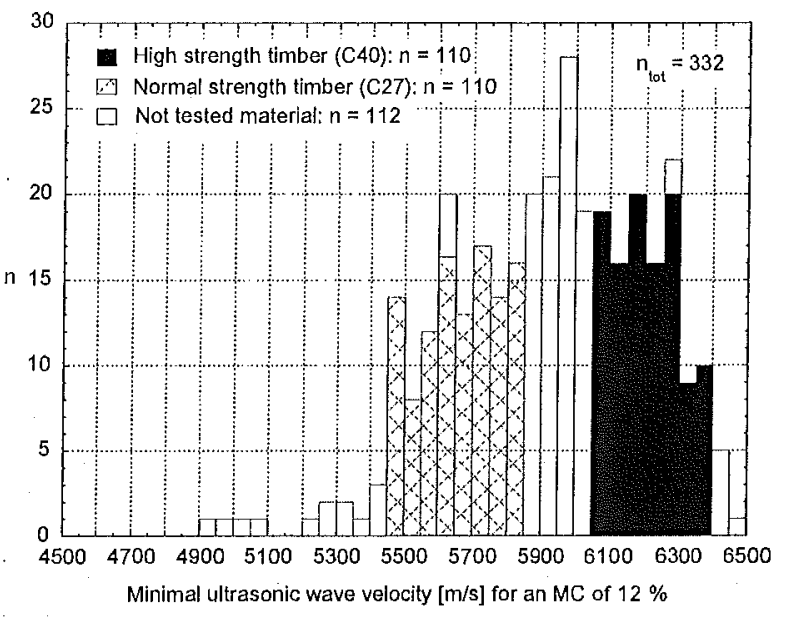

Fig. 6 - Ranking according to ultrasonic wave velocity $(\mathrm{MC}=$ moisture content).

\begin{tabular}{|c|c|c|c|c|}
\hline Sample & $\begin{array}{c}v_{12} \\
{[\mathrm{~m} / \mathrm{s}]}\end{array}$ & $\begin{array}{c}E_{\text {mean }} \\
{\left[\mathrm{N} / \mathrm{mm}^{2}\right]}\end{array}$ & $\begin{array}{c}E_{05} \\
{\left[\mathrm{~N} / \mathrm{mm}^{2}\right]}\end{array}$ & $C O V_{E}$ \\
\hline $\mathrm{C} 27$ & $5450-5850$ & 11100 & 8300 & $15.3 \%$ \\
\hline $\mathrm{C} 40$ & $6050-6400$ & 15300 & 11800 & $13.7 \%$ \\
\hline \multicolumn{5}{|c|}{$\begin{array}{l}v_{12}=\text { ultrasonic wave velocity for a moisture content of } 12 \% \\
E_{\text {mean }}=\text { mean value of modulus of elasticity (MOE) } \\
E_{05}=5^{\text {th }} \text { percentile of MOE } \\
C O V_{E}=\text { coefficient of variation of MOE }\end{array}$} \\
\hline
\end{tabular}

be described well by Equation (2) (see section 1).

\subsection{Magnification/reduction of initial moments}

The deflection of a structural member subjected to axial loads $N$ takes influence on the initial bending moment $M^{I}$, which in this test series is a consequence of the two lateral loads acting on the beam (see section 2.1 and Fig. 4). For elastic materials this effect can adequately be controlled by magnifying (in case of axial compression) or reducing (for axial tension) the initial moment $M^{I}$ to the extent of the axial 


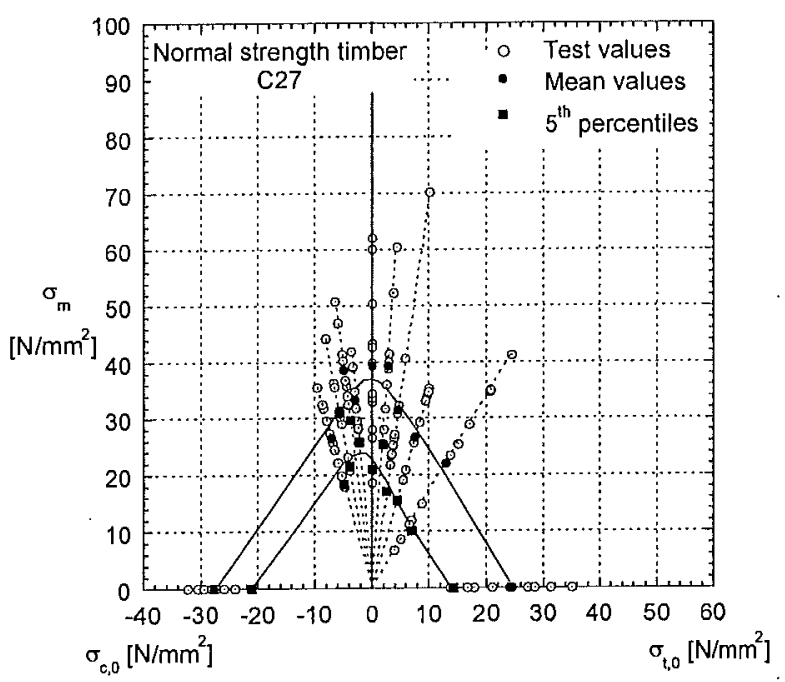

$\sigma_{c, 0}=$ compression stress parallel to the grain

$\sigma_{t, 0}=$ tension stress parallel to the grain

$\sigma_{m}=$ bending stress

Fig. 7 - Results of the $\mathrm{M} / \mathrm{N}$-interaction tests on normal strength timber (C27) together with interaction curves on the $5^{\text {th }}$ percentile and on the mean level.

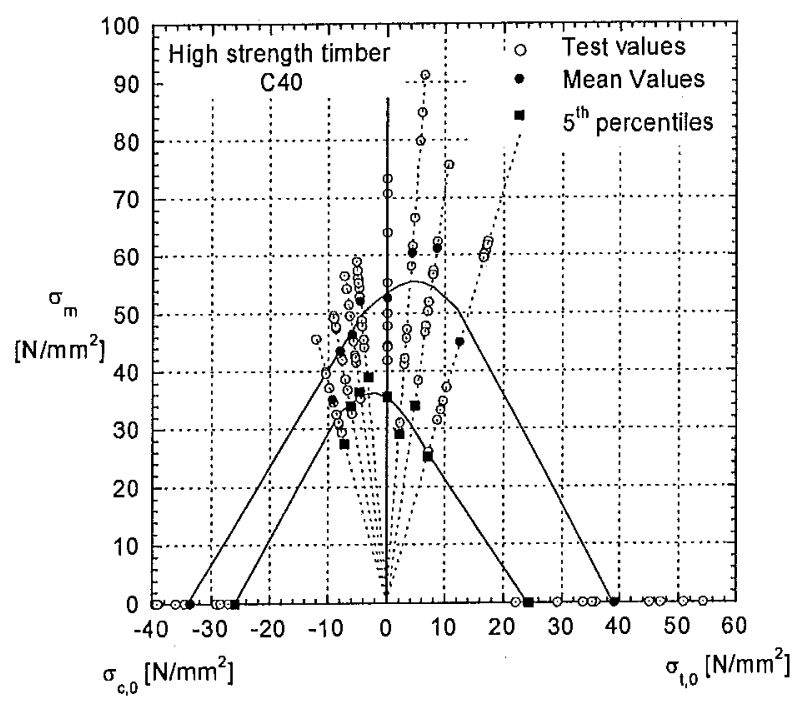

$\sigma_{c, 0}=$ compression stress parallel to the grain

$\sigma_{t, 0}=$ tension stress parallel to the grain

$\sigma_{m}=$ bending stress

Fig. 8 - Results of the M/N-interaction tests on high strength timber (C40) together with interaction curves on the $5^{\text {th }}$ percentile and on the mean level.

load $N$ multiplied by its eccentricity with respect to the axis of the beam. A magnified/reduced Moment $M^{I I}$ can be calculated using the factor $\varphi$ given by formula (3). This factor can be derived by solving the exact differential equation used to describe the problem. Tests on timber columns however show that the increase of $M^{I}$ can be considerably higher than given by Equation (3) due to "plastic" deformation of the compression portion of the cross-section. Buchanan therefore suggested Equation (4), which fitted his test results better [6].

$$
\begin{gathered}
\varphi=\frac{1}{1 \mp N / N_{e}} \\
\varphi=\frac{1+N / N_{e}}{1-N / N_{e}}
\end{gathered}
$$

$\varphi=$ magnification $(-) /$ reduction $(+)$ factor $N=$ axial force

$$
N_{e}=\frac{\pi^{2} \cdot E \cdot I}{\ell^{2}}=\text { Euler buckling load }
$$

$E=$ modulus of elasticity (MOE)

$I=$ moment of inertia

$\ell_{c r}=$ buckling length

Figs, 9 and 10 show how the calculations using both Equations (3) and (4) (based on the mean value of the modulus of elasticity) fit our experimental data for three exemplary ratios of axial and lateral forces $k=N / F=-3.0,-9.2$ and 2.4: For axial tension loads, Equation (3) corresponds well to the test results, whereas in case of compression forces the magnification is underestimated by Equation (3) because nonlinear deformations of the compression zone of the beam are not taken into account. The approach (4) on the other hand gives conservative results.

A reduction of the MOE in calculations of the Euler buckling load $N_{e}$ is another possibility to obtain better fit of the experimental results. In Figs. 11 and 12 the approaches (3) and (4) are compared. $N_{e}$ in formula (3) was calculated using either the mean value of MOE or a tangent modulus $T$ $\approx 0.8 E$. The tangent modulus method was introduced by Engesser for the design of steel columns [16]. The method is based on a reduced material stiffness above the so-called proportional limit, which mathematically can be described with a reduced MOE, the tangent modulus $T$. Engesser's theory was first questioned by other scientists but Shanley showed in 1947 [17], that Engesser's method was a valuable possibility to model the transition between stable and instable state of equilibrium for stocky, non-slender columns and to take into account plastic deformations of the compression zone.

According to [2] evaluations of member stability has to be performed using the $5^{\text {th }}$ percentile of the MOE $E_{05}$, which for solid timber is defined to be $2 / 3$ of $E_{\text {mean }}$ [15]. Since the MOE determines the problem in terms of strength rather than stiffness the calculation of the magnification factor has to be based on a lower-tail value rather than on the mean value of MOE, in order to reach an adequate level of safety.

At first sight the approaches look very similar but if we compare them in more detail, it is obvious that the traditional approach based on Equation (3) only gives safe results when calculated with a reduced $\mathrm{MOE}$, i.e. the tangent modulus $T=$ $0.8 \cdot E_{\text {mean }}$ or a $5^{\text {th }}$ percentile $E_{05}$. When basing the calculation of 


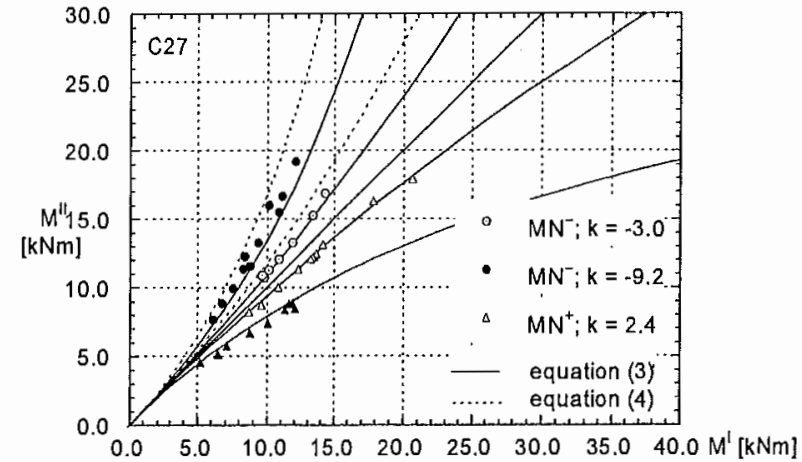

$M^{I}=$ initial bending moment

$M^{I I}=$ magnified/reduced bending moment

$k=$ ratio of axial force $N$ to lateral force $F$

Fig. 9 - Magnification/reduction of the initial bending moment $M^{l}$ for normal strength timber (C27).

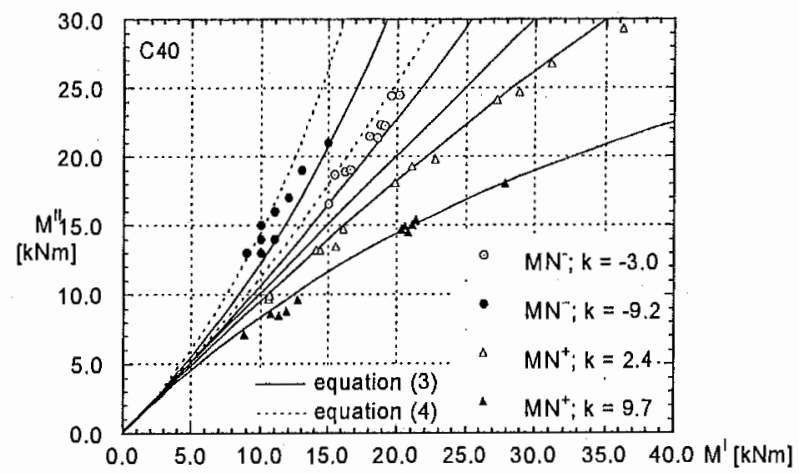

$M^{l}=$ initial bending moment

$M^{l l}=$ magnified/reduced bending moment

$k=$ ratio of axial force $N$ to lateral force $F$

Fig. 10 - Magnification/reduction of the initial bending moment $M^{I}$ for high strength timber (C40)

the magnification factor on the mean value of $\mathrm{MOE}$, Equation (4) must be made use of in order to get safe results.

\section{CONCLUSIONS}

When designing timber beams subjected to simultaneously acting bending moment and axial force, the magnification or reduction of the bending moment due to the eccentricity of the axial force has to be taken into account.

\subsection{Bending moment and tension force}

Interacting tensile force and bending moment on solid timber beams can be adequately handled by adding the two stress components:

$\frac{\sigma_{t, 0}}{f_{t, 0}}+\frac{\sigma_{m}}{f_{m}} \leq 1$

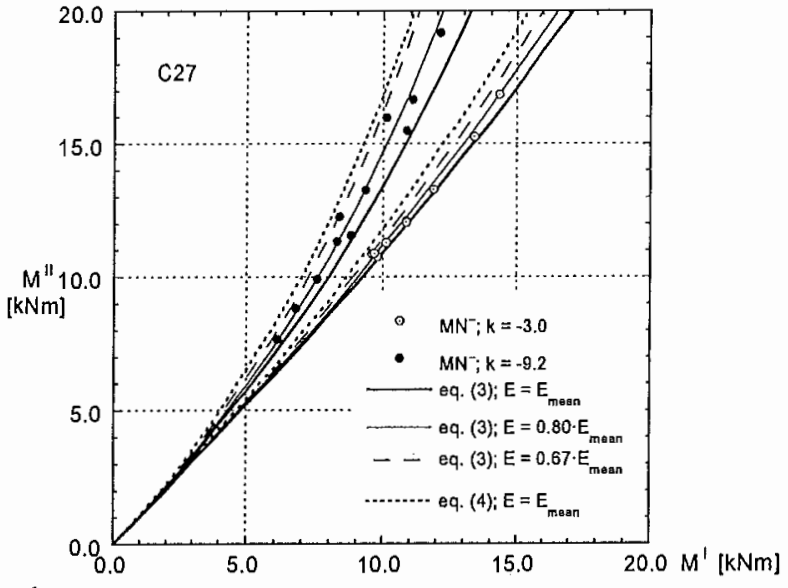

$M^{I}=$ initial bending moment

$M^{n}=$ magnified bending moment

$k=$ ratio of axial to lateral force

$E=$ modulus of elasticity (MOE)

$E_{\text {mean }}=$ mean value of $\mathrm{MOF}$

$E_{0 S}=5^{\text {th }}$ percentile of $\mathrm{MOE}$

Fig. 11 - Improved magnification factors for normal strength timber (C27)

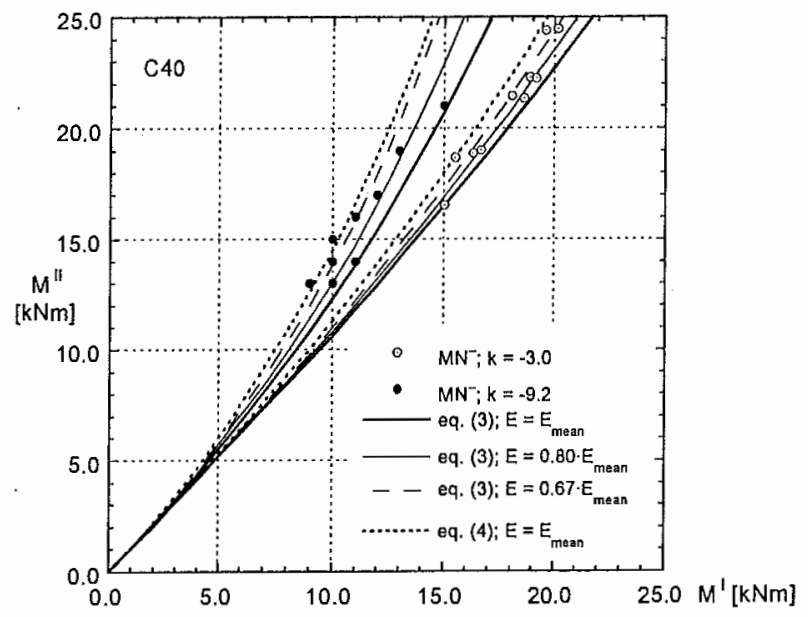

$M^{I}=$ initial bending moment

$M^{I l}=$ magnified bending moment

$k=$ ratio of axial to lateral force

$E=$ modulus of elasticity (MOE)

$E_{\text {mean }}=$ mean value of $\mathrm{MOE}$

$E_{0 S}=5^{\text {th }}$ percentile of $\mathrm{MOE}$

Fig. 12 - Improved magnification factors for high strength timber (C40)

The eccentric action of axial force can be compensated for by reduction of the initial bending moment with a reduction factor $\varphi$ :

$\varphi=\frac{1}{1+N / N_{e}}$. 


\subsection{Bending moment and compression force}

In case of interacting bending moment and compression force, the slenderness of the column plays a decisive role:

- Slender columns exhibit buckling failure. Since in practice perfectly straight columns loaded in pure axial compression do not exist, such members must always be designed considering both the compression load and the bending moment due to the compression force's eccentricity and geometrical imperfections. A linear interaction model is sufficient but the reduced resistance of the column due to buckling failure must be considered. The moment magnification factor has to be taken as

$$
\varphi=\frac{1}{1-N / N_{e}}
$$

and the Euler buckling load $N_{e}$ must be calculated on the basis of either the $5^{\text {th }}$ percentile of MOE or of a tangent modulus $T=0.8 \cdot E$.

Evaluating the magnification factor according to an approach by Buchanan [6]

$$
\varphi=\frac{1+N / N_{e}}{1-N / N_{e}}
$$

is another possibility. Using this approach the Euler buckling $N_{e}$ load is to be calculated on the basis of the mean value of MOE.

- Stocky, non-slender columns show a considerable nonlinearity of the $\mathrm{M} / \mathrm{N}$-interaction line due to non-linear, "plastic" deformations of the compression portion of the cross-section, especially for high bending moments and small to moderate compression forces. In this case linear adding of stress components is conservative. When superposing compression and bending stresses it is therefore suggested to use the following equation:

$$
\left(\frac{\sigma_{c, 0}}{f_{c, 0}}\right)^{2}+\frac{\sigma_{m}}{f_{m}} \leq 1 \text {. }
$$

\section{REFERENCES}

[1] Zakic, B.D., 'Inelastic bending of wood beams', Journal of the Aeronautical Sciences 12 (1945) 2079-2095.

[2] European Committee for Standardization CEN, 'EN 1995-1-1 Eurocode 5 Design of timber structures, Part 1-1: General Common rules and rules for buildings', 2003.

[3] Larsen, H.J. and Theilgaard, E., 'Laterally loaded timber columns', Journal of the Structural Division 105 (1979) 1347-1363.

[4] Senft, J.F. and Suddarth, S.K., 'Strength of structural lumber under combined bending and tension loading', Forest Products Journal 20 (1970) 17-21.

[5] Senft, J. F, 'Further studies in combined bending and tension strength of structural 2 by 4 lumber', Forest Products Journal 23 (1973) 36-41.

[6] Johns, K.J. and Buchanan, A.H., 'Strength of timber members in combined bending and axial loading', paper 24 in 'Proceedings of the IUFRO Timber Engineering Group Meeting', Sweden, 1982.

[7] Buchanan, A.H., Johns, K.C. and Madsen, B., 'Column design methods for timber engineering', Canadian Journal of Civil Engineering 12 (1985) 731-744.

[8] Buchanan, A.H., 'Combined bending and axial loading in lumber', ASCE Journal of Structural Engineering 112 (1986) 2592-2609.

[9] Blass, H.J., 'Ultimate loads of glulam columns', Bauingenieur 63 (1988) 245-251 [only available in German].

[10] Glos, P., 'Strength evaluation of glulam subjected to compression stress with special regard to load and material parameters', $\mathrm{PhD}$ thesis (Technical University of Munich, 1978) [only available in German].

[11] Kessel, M.H., Haller, P. and Bertolino, F., 'Experimental and numerical investigations on stocky columns of Swiss spruce timber', Bauingenieur 67 (1992) 277-281 [only available in German].

[12] Steiger, R., 'Equipment for tension testing of squared timber in structural dimensions', ETHZ-IBK-report 204, (Birkhäuser/ Springer, Basel, 1994) [only available in German].

[13] Steiger, R., 'Tests on solid spruce beams: Interacting bending moment and axial force', ETHZ-IBK-report 209 (Birkhäuser/Springer, Basel, 1995) [only available in German].

[14] Steiger, R., 'Mechanical properties of squared spruce beams subjected to flexural, tensile, compressive and combined $\mathrm{M} / \mathrm{N}$ loads', ETHZ-IBK-report 221, (Birkhäuser/Springer, Basel, 1996) [only available in German].

[15] European Committee for Standardization CEN, 'EN 338 Structural timber - strength classes', 2003.

[16] Engesser, F., 'Buckling', Schweizerische Bauzeitung 15 (25) (1895) 88 and 15 (26) (1895) 24.

[17] Shanley, F.R., 'Inelastic column theory', Journal of the Aeronautical Sciences 14 (1947) 261-267. 
